\title{
Evaluation of potential specie for use in safety curtains for forest fire prevention
}

Victor Magario Corsini ${ }^{1 *}$; Thainá Aloiso Saraiva ${ }^{1}$; Vitoria de Menezes Furlan ${ }^{l}$; Alexandre França Tetto ${ }^{l}$; Bruna Kovalsyki ${ }^{1}$

\footnotetext{
${ }^{1}$ Universidade Federal do Paraná (UFPR), Curitiba, Brazil

* e-mail: victor222087@ hotmail.com
}

\begin{abstract}
In urban-rural interfaces, the threat of forest fires to properties, human life, as well as biodiversity is worrying, so different techniques have been developed to mitigate or prevent possible damage. One of these is the use of safety curtains, which are plantings in strips of species with less flammability than the main cultivation, in order to reduce or prevent the spread of fire and may also have overall conservation benefits. Its use has been recommended worldwide, but there are still few tests performed regarding its use. This study aimed to evaluate the flammability of Ocotea porosa (Imbuia) specie to compose safety curtains. Fifty replications of epiradiator burns $\left(250\right.$ to $\left.350^{\circ} \mathrm{C}\right)$ were performed with $1 \mathrm{~g}$ of freshly collected mature leaves (up to 2 hours after collection). The ignition frequency (FI) in percentage, the ignition time (TI) in seconds, the combustion duration (DC) in seconds, the combustion index (IC) determined by the flame height in centimeters and, Finally and the flammability (VI) value, established through FI and IT, were analyzed. The results showed the following values: $\mathrm{FI}=96 \%, \mathrm{TI}=32.5 \mathrm{~s}, \mathrm{DC}=17.9 \mathrm{~s} \mathrm{IC}=4$ (high) and $\mathrm{VI}=2$ (moderately flammable). It can be concluded that Ocotea porosa has potential to compose safety curtains, however, calorimetric and combustibility analyzes are recommended in order to reinforce the results of the present study.
\end{abstract}

Keywords: preventive forestry, forest protection, green barriers. 